Revista Aspas

ppgac - USP

Artigo

\title{
PARTICULARIDADES DA LEI DE FOMENTO AO TEATRO PARA A CIDADE DE SÃO PAULO
}

PARTICULARITIES OF THE LAW OF THEATRE PROMOTION TO THE SÃO PAULO CITY

PARTICULARIDADES DE LA LEY DE FOMENTO AL TEATRO PARA LA CIUDAD DE SÃO PAULO

Simone do Prado Romeo

Simone do Prado Romeo

Doutoranda em Artes Cênicas

Escola de Comunicações e Artes da USP; Pesquisa de doutorado em andamento orientação Prof. Elizabeth F. C. R. Azevedo.

E-mail: simoneromeo@usp.br 


\section{Resumo}

Este artigo debate a Lei de Fomento ao Teatro para a cidade de São Paulo sob a ótica de que ela representa uma inovação no campo das políticas culturais brasileiras. Sendo assim, discutiremos os principais aspectos dessa lei, incluindo os critérios de percepção e apreciação que ela fixa, e que foram interpretados por nós enquanto um conjunto de afirmações que revelam uma nova legitimidade em matéria de teatro. A partir do exame dessa lei e de suas particularidades pretendemos demonstrar, ainda, que as políticas culturais são detentoras de poder simbólico atuante no campo cultural.

Palavras-chave: critérios de percepção e apreciação teatral, hierarquias simbólicas, políticas culturais

\section{Abstract}

This article discusses the Law for the Promotion of Theater for the São Paulo city from the perspective that it represents an innovation in the field of Brazilian cultural policies. Thus, we will discuss the main aspects of this law, including the criteria of perception and appreciation that it sets interpreted by us as a set of statements that reveal a new legitimacy in theater. From the examination of this law and its particularities we intend to further demonstrate that cultural policies have symbolic power acting in the cultural field.

Keywords: criteria of theatrical perception and appreciation, symbolic hierarchies, cultural policies

\section{Resumen}

Este artículo aborda la Ley de Fomento al Teatro para la ciudad de São Paulo desde la perspectiva de que ella representa una innovación en el campo de las políticas culturales brasileñas. Por lo tanto, discutiremos los principales aspectos de esta ley, incluyendo los criterios de percepción y apreciación que establece, interpretados por nosotros como un conjunto de declaraciones que revelan una nueva legitimidad en materia de teatro. Del examen de esta ley y sus particularidades pretendemos demostrar, además, que las políticas culturales tienen un poder simbólico que actúa en el campo cultural.

Palabras clave: criterios de percepción y apreciación teatral, jerarquías simbólicas, políticas culturales. 
Não é novidade que a Lei de Fomento ao Teatro para a cidade de São Paulo' representa uma inovação no contexto brasileiro, seja por constituir a primeira política cultural em nosso meio destinada a fomentar processos de pesquisa e criação e não apenas os seus resultados finais; seja, ainda, porque ela foi elaborada pelos próprios artistas que, através da atuação em torno ao Arte contra a Barbárie ${ }^{2}$, chegaram a elaboração e aprovação de uma política cultural que vincula orçamento público direto com vistas a apoiar um setor específico da produção, conhecido por teatro de grupo ou de pesquisa. Tal política instituiu o principal programa público de apoio ao teatro de que se tem notícia no Brasil, tornando-se um marco no âmbito das políticas de cultura entre nós e modelo de política cultural mais independente das injunções de mercado. A partir de sua aprovação, em 2002, observa-se a institucionalização de um modo de organização do trabalho teatral muito distinto das companhias convencionais. E, se a maneira como se organizam as relações de produção impacta nos processos criativos e nos resultados da obra, a existência dessa política, cujas características examinaremos a seguir, produziu diversos impactos sobre o campo teatral em questão e, por isso, merece ser examinada. Partindo desses pressupostos, este artigo debate os principais aspectos da lei, ressaltando suas particularidades com vistas a demonstrar sua relevância para o contexto local.

A primeira característica notória da Lei de Fomento, conforme apontamos, é que ela foi elaborada pelos próprios produtores que, através de suas lutas em torno ao Arte contra a Barbárie, foram responsáveis tanto pela elaboração da lei como pelas lutas por sua aprovação. Até então, o que havia de participação direta de artistas na formulação de políticas setoriais em nosso

\footnotetext{
' Lei Municipal 13.279 de 08 de janeiro de 2002. Daqui por diante, iremos nos referir a ela apenas por Lei de Fomento, maneira como é comumente conhecida.

${ }^{2}$ Nos referimos ao Arte contra a Barbárie, movimento que surgiu, de forma embrionária, em 1998 a partir da reunião de artistas ligados a coletivos teatrais da cidade (Teatro União e Olho Vivo, Companhia do Latão, Folias D'Arte, Parlapatões, Pia Fraus e Grupo Tapa, Parlapatões), além de intelectuais e artistas sem o mesmo vínculo, mas de longa e reconhecida trajetória no campo das artes cênicas, (dos quais Aimar Labaki, Fernando Peixoto, Gianni Ratto e Umberto Magnani). A partir de 1999, através da publicação de manifestos e da promoção de debates públicos, o movimento atingiu grande visibilidade pública, ampliando seus quadros e tornando-se referencial no campo artístico ao pautar os debates sobre política cultural, além de expor publicamente o caráter injusto das leis de incentivo fiscal. Para uma análise mais aprofundada sobre o Arte contra a Barbárie, ver ROMEO, 2016.
} 
meio se dava em termos de reivindicações mais ou menos pontuais destinadas a algum político da ordem que, a depender do jogo de interesses, acatava algumas demandas do setor cultural. Tal foi o caso da relação de parte da categoria teatral com o governo Vargas através do Serviço Nacional de Teatro (SNT), para citar tão só um exemplo (CAMARGO, 2017).

Também no caso da articulação e das mobilizações que resultaram na Lei de Fomento, se consideramos o caráter público tanto das críticas ${ }^{3}$ quanto das reivindicações ${ }^{4}$, pode-se dizer que uma fronteira foi transgredida. Conforme apontou o filósofo Paulo Arantes em conhecida entrevista (NÉSPOLI, 2019), em vista do cenário de ruínas em que se encontrava a cultura ao final dos anos 1990, a reação dos grupos de São Paulo que, articulados como um setor social, conseguiram arrancar do Estado uma lei de fomento, representou a transposição de um limiar histórico, ainda que irrisório. Com efeito, as lutas empreendidas pelo Arte contra a Barbárie produziram impactos em todo o campo artístico, inspirando artistas de outras áreas e impulsionando a criação de outras políticas setoriais à sua semelhança ${ }^{5}$.

Outro aspecto notório da política em pauta, que igualmente deriva do fato de ela ser o resultado de lutas empreendidas por um setor específico da produção, é que ela não se destina ao teatro como um todo. Característica que, em si, não constitui novidade, já que de maneira geral toda política cultural classifica e privilegia determinado segmento da produção. Entretanto, geralmente isso acontece de forma mais ou menos dissimulada, através de vetos indiretos e em acordo com os interesses da administração, e não como resultado da reivindicação pública dos interessados. Nesse sentido, a lei de fomento pode ser vista como produto de uma relação de novo tipo entre o

\footnotetext{
${ }^{3}$ Destinadas a denunciar a situação da cultura naquele momento, depois do impulso dado ao incentivo fiscal no âmbito das políticas de cultura compreendidas, então, como um "bom negócio" tal qual pregava a cartilha lançada por Francisco Weffort, ministro da cultura durante os dois mandatos FHC (1995-2003). Na famosa cartilha "Cultura é um bom negócio", o ex-ministro defendia abertamente os incentivos fiscais e o marketing cultural enquanto pilares das políticas para o setor.

${ }^{4}$ Nos referimos, fundamentalmente, às reuniões que que posteriormente ficaram conhecidas como "Espaço da Cena", aos três manifestos publicados pelo movimento em um jornal de grande circulação e à produção do jornal O Sarrafo.

${ }^{5}$ Como o Fórum de Cinema e outras leis de fomento mais ou menos derivada daquela: a Lei de Fomento à Dança, o Fomento às Periferias, Fomento ao Circo etc. Sendo que existe, hoje, um departamento de fomentos (no plural) no âmbito da Secretaria Municipal de Cultura.
} 
campo cultural e campo do poder, além de ser a primeira expressamente destinada a uma fração específica da produção segundo critérios estabelecidos por ela própria. Conforme esclareceu Reinaldo Maia ${ }^{6}$, "os grupos tinham consciência que não representavam a produção cênica da cidade de São Paulo. [...] Viam-se como uma parcela significativa, mas em uma situação muito singular em relação ao todo da produção [...]" (MAIA, 2006, s/p.). Todavia, no âmbito das ações do poder público e de seu orçamento, seria preciso justificar a validade de subsidiar esse fazer teatral em detrimento de outros, legitimando-o, portanto. O principal argumento para tanto foi decantado do discurso artístico que se opõe ao mercado e que, assim, procura estabelecer o estatuto superior da arte, nesse caso, identificada ao teatro de pesquisa.

\section{O teatro fundamental para a cidade}

Conforme as discussões acumuladas no âmbito do movimento dos grupos, que incluíam temas relacionados à ética (e estética) e à função social do teatro, chegou-se à argumentação de que o teatro de pesquisa era digno de receber financiamento público direto porque representava o "teatro fundamental para a cidade". De acordo com um texto elaborado para discussão nos fóruns do movimento ${ }^{7}$, partiu-se do entendimento de que

[...]são esses coletivos e o seu trabalho contínuo que podem constituir e manter um teatro vital para a Cidade. Caso contrário, o programa não passaria de um apoio assistencial, parcial, corporativo, a um segmento da produção teatral. Logo, o fomento é um programa que pretende consolidar um teatro fundamental para a cidade, através de recursos permanentes do município, e diz que esse é o papel dos núcleos artísticos com propostas de trabalho continuado [...] Pode-se dizer que o teatro fundamental para a

\footnotetext{
${ }^{6} \mathrm{Em}$ documento que pertence ao arquivo pessoal do artista, falecido em 2009, e que nos foi gentilmente cedido por sua ex-esposa, Giselda Pereira, a quem agradecemos. Não sabemos se o texto foi publicado, utilizamos a data contida no manuscrito.

${ }^{7}$ Texto sem título. s.d. Acervo Arte contra a Barbárie. Arquivo Multimeios, Centro Cultural São Paulo. Tal acervo ainda não foi tombado ou catalogado, fato que nos impossibilita de fazer referência mais precisa. Nesse caso, acreditamos se tratar de um documento explicativo, elaborado pelo grupo de trabalho responsável pela elaboração do programa de fomento, para debate nos fóruns do movimento.
} 
cidade implica mexer nas relações de trabalho e nas técnicas de criação [e que] trabalho continuado implica expectativas, comportamentos, ações, éticas, relações de trabalho e mando, divisão do dinheiro, técnicas e mesmo objetivos diferentes daqueles que norteiam um profissional dentro da produção da novela, do musical da Broadway, da comédia de gabinete, por exemplo. [...] $\mathrm{O}$ que se espera é que elas [relações de trabalho continuado] possibilitem e exijam a criação de outras poéticas, adequadas a essas formas de trabalho e criação. (Arte contra a Barbárie, s/d).

Segundo o texto da lei, ela se destina as "Núcleos Artísticos", que constituam uma "base organizativa com caráter de continuidade" (São Paulo, Lei 13.279/02, Art. 5) indicando, assim, uma mudança fundamental com relação ao eixo de produção teatral dominante, caracterizado pela junção temporária de artistas e técnicos contratados para realizar um trabalho pontual.

Em conformidade com tal definição, a lei de fomento não postula qualquer orientação de gênero ou de repertório. Em lugar disso, temos a legitimação de um modo de produção específico que, segundo argumentação, seria o único capaz tanto de gerar novas poéticas quanto de criar novas relações com o público e, portanto, com a cidade, tornando-se assim fundamental à ela e justificando a aplicação de verbas do município. Tratase, assim, de uma visão e de uma posição artística que pretende consolidar um teatro fundamental para a cidade e seus moradores através do estabelecimento de princípios criativos fundamentados pela pesquisa de linguagem e pela continuidade do trabalho artístico, os quais seriam capazes de inverter os significados tradicionais do teatro habilitando-o a gerar uma nova relação com a cidade e seus moradores.

Nos termos da lei, entende-se por pesquisa as "práticas dramatúrgicas ou cênicas que não se aplica à pesquisa teórica restrita à elaboração de ensaios, teses, monografias e semelhantes, com exceção daquela que se integra organicamente ao projeto artístico" (São Paulo, Lei 13.279/02). Ainda que se diferencie a pesquisa cênica daquela de cunho acadêmico, é possível estabelecer paralelos entre uma prática e outra. Sobre isso, certamente contribui o fato de que grande parte dos grupos têm origem na universidade,

\footnotetext{
8 - Estipuladas "anualmente [em] item próprio no orçamento da Secretaria Municipal de Cultura com valor nunca inferior a $\mathrm{R} \$ 6.000 .000,00$ (seis milhões de reais)" (São Paulo, 13.279/02, Art. $2^{\circ}$ )
} 
além de haver diversos artistas ligados ao teatro de grupo que desenvolvem pesquisa acadêmica, conciliando-a com a prática artística. Em entrevista já citada, o filósofo Paulo Arantes observou tal similitude, chamando a atenção para o fato de que "o espírito da lei lembra muito o de uma agência pública de amparo à pesquisa" (NÉSPOLI, 2007, p.175), referindo-se ao CNPq. Com efeito, de maneira semelhante ao financiamento público à pesquisa acadêmica, na base da lei de fomento está a reivindicação de um tempo alargado para a pesquisa de linguagem, que necessitaria de um "tempo despendido na investigação e na exploração temática [que envolve] uma dramaturgia em processo" (ARAUJO, 2006, p. 132). Considerando, ainda, que no geral esses processos de investigação cênica exigem muito mais tempo e dedicação dos artistas envolvidos, eles só se tornam possíveis quando há instituições dispostas a financiar a produção, de modo análogo ao campo científico. Se é assim, através do apoio sistemático aos grupos de teatro, a Lei de Fomento teria fornecido condições sociais e materiais para que o teatro de pesquisa se difundisse em nosso meio, fazendo da capital paulista uma espécie de laboratório compulsório de investigações cênicas, muitas vezes transgressoras.

\section{Critérios de apreciação e seleção}

Convém iniciar esse debate explicitando a maneira com que as comissões julgadoras são formadas, outro aspecto singular da política em debate. A lei estabelece que tais comissões serão constituídas por sete membros com "notório saber em teatro", sendo quatro deles nomeados diretamente pelo Secretário Municipal de Cultura, incluindo o presidente, com poder de voto apenas em caso de desempate. Já os outros três membros são escolhidos pelos próprios proponentes, com o direito de votar em até três nomes de uma lista de candidatos previamente indicados pelas entidades de caráter representativo em teatro sediadas no Município de São Paulo há mais de 3 (três) anos. Não temos notícia de outra política cultural em nosso meio na qual o julgamento dos interessados seja realizado a partir de princípios 
democráticos e paritários, nos quais a autonomia artística é observada também nos processos de julgamento e seleção.

Feita essa ressalva, convém examinar propriamente os critérios estabelecidos pela lei, à luz do contexto mais amplo do qual participam. Uma tal abordagem permitirá apreender o jogo simbólico a partir do qual grupos e projetos são classificados como artísticos e nesse caso, socialmente relevantes para a cidade. Dessa perspectiva, dentre os 27 artigos que compõe a lei há um que merece atenção, posto que estabelece os critérios de seleção a serem adotados pela comissão julgadora e que, dessa forma, condensam os princípios dessa nova legitimidade em matéria de teatro. São eles:

\footnotetext{
I - Os objetivos estabelecidos no artigo $1^{\circ}$ desta lei.

II - Planos de ação continuada que não se restrinjam a um evento ou uma obra.

III - A clareza e qualidade das propostas apresentadas.

IV - O interesse cultural.

V - A compatibilidade e qualidade na relação entre prazos, recursos e pessoas envolvidas no plano de trabalho.

VI - A contrapartida social ou benefício à população conforme plano de trabalho.

VII - O compromisso de temporada a preços populares quando o projeto envolver produção de espetáculos.

VIII - A dificuldade de sustentação econômica do projeto no mercado. (São Paulo, lei 13.279/02, Art. 14)
}

O item I retoma o Artigo 1ำ da lei, o qual estabelece que seu objetivo é "apoiar a manutenção e criação de projetos continuados de pesquisa e produção teatral visando o desenvolvimento do teatro e o melhor acesso da população ao mesmo" (LEI 13.279/02). Define-se, assim, o trabalho continuado, tanto da pesquisa quanto do núcleo artístico, como principal vetor da produção digna de receber fomento público, revelando a concepção de que o teatro detentor de valor simbólico deve ser produzido a partir da pesquisa coletiva e continuada de atores, dramaturgo, encenador etc. Estes devem ser ordenados dentro de um núcleo também de base durável, em acordo com os pilares do "processo colaborativo" - cujos adeptos ficaram conhecidos por teatro de grupo. Trata-se de uma produção que se pretende autônoma e que reivindica um ciclo longo de produção que, nesses casos, inclui pesquisa de conteúdo, improvisação na sala de ensaios e diferentes formas de estímulo à imaginação e invenção coletivas, em oposição à ortodoxia teatral ou ao 
sistema quase fabril de montagem de espetáculos que rege a indústria do entretenimento. Dessa forma, afirma-se a superioridade da produção continuada em oposição ao modo de produção teatral dominante. Cabe destacar que esse procedimento criativo, por nós mal esboçado, constitui um princípio geral e que a maneira com que cada grupo opera com eles, assim como o produto final desses trabalhos de investigação cênica, são muito diversos.

Assim, parece que se por um lado temos a ausência de orientação quanto ao repertório, por outro, a legitimação de um procedimento artístico, o "trabalho continuado", já precipitaria o seu conteúdo. Somado a esse modo específico de organização do trabalho teatral, que prevê "planos de ação continuada que não se restrinja a um evento ou a uma obra" os projetos aprovados pela Lei de Fomento também devem cumprir com os demais critérios dessa legitimidade artística.

No caso das alíneas III, IV e V, que versam sobre a clareza e qualidade das propostas apresentadas, seu interesse cultural, compatibilidade e qualidade na relação entre prazos, recursos e pessoas envolvidas no plano de trabalho etc., tratam-se critérios mais consensuais que visam assegurar a racionalidade e operacionalidade do programa. Que, como qualquer política pública, precisa corresponder às expectativas em termos de qualidade e exequibilidade, que devem ser demonstradas pelo proponente e são pontos pacíficos na avaliação de projetos de qualquer natureza.

Menos consensual é o item $\mathrm{Vl}$, através do qual fica estabelecido que os projetos contemplados devem assegurar alguma "contrapartida social ou benefício à população conforme plano de trabalho", sugerindo uma relação entre arte e ação social. Questão que deu margem à inúmeros debates mas, considerando o contexto histórico de sua elaboração, é possível supor que a fixação de tal critério deriva, sobretudo, da oposição às políticas de incentivo fiscal, já que uma das principais denúncias que se fazia à época consistia no fato de que, apesar de se tratar de dinheiro público que de outra forma seria revertido em impostos, a maioria dos espetáculos incentivados via renúncia fiscal não ofereciam nenhuma contrapartida aos cidadãos. Assim, em se tratando de orçamento público e de uma política ao teatro, mas para a cidade, 
partiu-se do entendimento de que o teatro legítimo de receber financiamento direto deveria promover algum benefício à população.

Além da ausência de contrapartidas, outra crítica corrente às políticas de renúncia fiscal dizia respeito ao alto valor praticado pelos ingressos, que acabam alijando a maior parte da população da fruição cultural. Contrapondose a isso, ficou estabelecido que a programação fomentada deveria assumir o compromisso de temporada a preços populares, no caso de projetos que envolvem a produção de espetáculo, conforme item VII. Por fim, mas não menos importante, está a necessidade expressa de que os projetos contemplados demonstrem dificuldade de sustentação econômica no mercado, oposição estruturante das lutas que culminaram na Lei de Fomento.

Em suma, trata-se de uma percepção artística que conjuga, ao mesmo tempo, o privilégio do caráter continuado do trabalho - segundo a convicção de que ele seria capaz de gerar retornos sociais - à exigências formais, como a clareza da proposta, sua viabilidade e adequação de prazos e recursos, critérios consensuais dentro desse universo. Assim foram consolidados os pressupostos do teatro digno de receber as verbas do município, segundo uma concepção que os próprios artistas produziram de si e de seu trabalho e que foram responsáveis por produzir uma nova legitimidade em matéria de teatro (ROMEO, 2016). Passadas quase duas décadas de sua aprovação, tem sido corrente as avaliações de que depois da lei do fomento "o teatro na cidade já é outro" (PIACENTINI, 2012, p.11) ou, até, que "o teatro de grupo [...] constitui a forma teatral dominante no município" (FREIRE, 2017, p. 206). Proposições que, ainda que precisem ser matizadas, corroboram tanto a eficácia simbólica das lutas promovidas pelos grupos quanto o poder de legitimação e consagração que envolve a consecução de qualquer política cultural, com seu caráter ordenador e classificatório.

\section{Referências Bibliográficas}

ARAÚJO, Antônio. O processo colaborativo no Teatro da Vertigem. Revista Sala Preta, ํㅜ 6 , pp. 127-133. Disponível em http://www.revistas.usp.br/salapreta/article/view/57302, consultado em 26 de março de 2019. 
BRASIL. Cultura é um bom negócio. Ministério da Cultura, Brasília, 1995. Disponível em: http://www.consultaesic.cgu.gov.br/busca/dados/Lists/Pedido/Attachments/460766/RESPOS TA PEDIDO Banco\%20de\%20Projeto\%20-\%20Cultura\%20bom\%20negcio-1995.pdf, consultado em 26 de dezembro de 2019.

CAMARGO, Angélica Ricci. Arquivos institucionais e a história do teatro no Brasil: o caso do Serviço Nacional de Teatro (SNT). Revista Sala Preta, vol. 17, n. 2, 2017. Pp. 165-180. FREIRE, Vítor. Reflexões sobre os esforços na formação de plateias para o teatro paulistano. Revista Sala Preta, vol. 17, no 1: 2017, pp. 204-216.

SÃO PAULO (Cidade). Lei no 13.279, de 08 de janeiro de 2002. Institui o "Programa Municipal de Fomento ao Teatro para a Cidade de São Paulo" e dá outras providências. Disponível em: https://www.prefeitura.sp.gov.br/cidade/secretarias/cultura/noticias/?p=7298, consultada em 26 de março de 2019.

MAIA, Reinaldo. Arte e Barbárie. Arquivo pessoal do autor: agosto de 2006.

NÉSPOLI, Beth. Paulo Arantes: um pensador na cena paulistana. O Estado de São Paulo, 15 de julho de 2007. Caderno 2, p. 175. Disponível em:

https://acervo.estadao.com.br/pagina/\#!/20070715-41543-nac-175-cd2-d8-not, consultado em 26 de março de 2019.

PIACENTINI, Nei. Apresentação. In: COSTA, Iná Camargo \& CARVALHO, Dorberto. A luta dos grupos teatrais de São Paulo por políticas públicas para a cultura: os cinco primeiros anos da lei de fomento ao teatro. São Paulo: Cooperativa Paulista de Teatro, 2008 ROMEO. Simone do Prado. O movimento Arte contra a Barbárie: gênese, estratégias de legitimação e princípios de hierarquização das práticas teatrais em São Paulo (1998-2002). Guarulhos, 2016. 229 f. Dissertação (Mestrado em Ciências Sociais) - Escola de Filosofia, Letras e Ciências Humanas, Universidade Federal de São Paulo. 